\title{
Penerapan Kesehatan Dan Keselamatan Kerja (SMK3) (Studi Kasus Pada Pembangunan Gedung Rawat Inap RSUD Dr. Achmad Mochtar Bukittinggi)
}

\author{
Fatma Ira Wahyuni ${ }^{1}$ dan Refly Afrilia ${ }^{2}$ \\ Email: fatmairawahyuni@gmail.com \\ ${ }^{1}$ Dosen Prodi Teknik Sipil dan ${ }^{2}$ Mahasiswa Prodi Teknik Sipil \\ Sekolah Tinggi Teknologi Payakumbuh, Jl. Khatib Sulaiman, Sawah Padang, Payakumbuh \\ Indonesia
}

\begin{abstract}
ABSTRAK
Penelitian tentang Penerapa Kesehatan dan Keselamatan Kerja (SMK3) (Studi kasus pada pembangunan Gedung Rawat Inap RSUD dr. Achmad Mochtar Bukittinggi) telah dilakukan guna mengetahui penerapan Sistem Manajemen Kesehatan dan Keselamatan Kerja (SMK3) pada pelaksanaan Proyek Pembangunan Gedung Rawat Inap RSUD Dr. Achmad Mochtar Bukittinggi dan untuk mengetahui apakah kontraktor pada proyek Pembangunan Gedung Rawat Inap RSUD Dr. Achmad Mochtar Bukittinggi telah menerapkan Sistem Manajemen Kesehatan dan Keselamatan Kerja dalam proses pembangunannya. Metode pengumpulan data yang digunakan dalam penelitian ini adalah data primer dan data sekunder. Dari segi proses pelaksanaan pengumpulan data, dengan dokumentasi dan observasi. Pengolahan data menggunakan program statistik SPSS 13. Hasil menunjukkan bahwa Penerapan Sistem Manajemen Kesehatan dan Keselamatan Kerja (SMK3) pada proyek ini kurang diterapkan, hal ini terlihat dari jawaban dan tanggapan dari unsur perusahaan dan unsur pekerja yang setelah dirata-ratakan didapat persentase 26.13\%. Kontraktor pada Pembangunan Gedung Rawat Inap RSUD Dr. Achmad Mochtar Bukittinggi menurut penelitian yang didapatkan tidak menerapkan Sistem Manajemen Kesehatan dan Keselamatan Kerja (SMK3) dalam proses pembangunan.
\end{abstract}

Kata Kunci : SMK3, Alat pelindung diri, Perusahaan Konstruksi

\section{PENDAHULUAN}

Masalah Kesehatan dan

Keselamatan Kerja (K3) kurang mendapat perhatian dari berbagai pihak, baik pekerja, kontraktor mapun pemerintah. Kurangnya kesadaran akan pentingnya $\mathrm{K} 3$ ini yang menyebabkan banyaknya terjadi kecelakaan pada saat bekerja. Untuk mencegah terjadinya kecelakaan kerja perlu adanya Sistem Manajemen Kesehatan dan Keselamatan Kerja (SMK3) yang baik bagi perusahaan jasa konstruksi.Ramadhan (2012) melaporkan tentang kurangnya kesadaran individu akan pentingnya kesehatan dan keselamatan kerja (K3) terutama disiplin penggunaan alat perlindungan diri pada proyek pembangunan jalan Rawa Buaya Cengkareng. Pangkey, dkk (2012) dalam penelitiannya tentang Penerapan Sistem Manajemen Keselamatan Dan Kesehatan Kerja (Smk3) Pada Proyek Konstruksi Di Indonesia (Studi Kasus: Pembangunan Jembatan Dr. Ir. Soekarno-Manado) mengatakan bahwa Sistem Manajemen Keselamatan dan Kesehatan Kerja (SMK3) merupakan sistem perlindungan bagi tenaga kerja dan jasa konstruksi untuk meminimalisasi dan menghindarkan diri dari resiko kerugian moral maupun material, kehilangan jam kerja, maupun keselamatan manusia dan lingkungan sekitarnya yang nantinya dapat menunjang peningkatan kinerja yang efektif dan efisien. Pedoman penerapan SMK3 di Indonesia diatur dalam Peraturan Menteri Tenaga Kerja Nomor: PER.05/MEN/1996.

Selanjutnya pada tahun yang sama (2012) Messah, dkk melakukan Suatu Kajian Implementasi Sistem Manajemen Keselamatan Dan Kesehatan Kerja Pada Perusahaan Jasa Konstruksi Di Kota Kupang. Messah (2012) menjelaskan bahwa implementasi SMK3 perusahaan jasa konstruksi di Kota Kupang termasuk dalam kategori kuning dengan prosentase 62,38\% dan tingkat kecelakaan masuk dalam 
kategori hijau maka implementasi SMK3 berada pada level 2 (cukup aman). Ketentuan-ketentuan SMK3 sebagian besar telah dilakukan oleh perusahaan jasa konstruksi. Sepuluh ketentuan yang paling banyak diterapkan adalah menetapkan kebijakan K3, mengidentifikasi bahaya yang akan terjadi, menyediakan dana untuk pelaksanaan K3, menentukan pengendalian resiko kecelakaan, peraturan yang dibuat berdasarkan perundang-undangan mengenai $\mathrm{K} 3$, menyediakan fasilitas P3K dalam jumlah yang cukup, membuat tujuan dan sasaran yang ingin dicapai, setiap pihak yang terlibat dalam perusahaan jasa konstruksi harus berperan dalam menjaga dan mengendalikan pelaksanaan $\mathrm{K} 3$, adanya pembagian tugas dan tanggung jawab yang jelas dan implementasi pengendalian untuk mengelola bahaya K3. Susihono (2013) melakukan penelitian tentang Penerapan Sistem Manajemen Keselamatan dan Kesehatan Kerja (K3) Dan Identifikasi Potensi Bahaya Kerja (Studi Kasus Di Pt. Ltx Kota CilegonBanten) dengan hasilnya menunjukkan bahwa penerapan SMK3 telah sesuai dengan undang-Undang yang berlaku, namun nilai resiko potensi bahaya bagian fluid utility menunjukkan tingkat keparahan bahaya kerja kecil dan kemungkinan terjadinya potensi bahaya kerja juga kecil, nilai kategori potensi bahaya kerja perlu dikendalikan dengan prosedur rutin. Faktor penyebab potensial terjadinya potensi bahaya adalah suara mesin bising, Standard Operational procedure (SOP) belum terpasang secara ergonomis, terdapat benda asing yang menghalangi jalan, temperatur ruangan meningkat 50C dari temperatur normal.

$$
\text { Penelitian mengenai K3 }
$$

Keselamatan dan Kesehatan Kerja (K3)) selain yang telah diuraikan di atas masih banyak dilaporkan, diantaranya : Implementasi Keselamatan Dan Kesehatan Kerja (K3) Pada Proyek Di Kota Bitung (Studi Kasus Proyek Pembangunan Pabrik Minyak Pt.Mns) oleh Sihombing (2014). Selanjutnya Thaufik (2015) melakukan Penelitian tentang Tinjauan Penerapan Sistem Manajemen Keselamatan Dan Kesehatan Kerja (Smk3) (Studi Kasus: Pembangunan Gedung Telkomsel
Pekanbaru) oleh Thaufik (2015). Penerapan K3 (Keselamatan dan Kesehatan Kerja) sangat penting untuk dilakukan dalam setiap pembangunan proyek kontruksi. Pembangunan gedung rawat inap pada RSUD Dr. ACHMAD MOCHTAR, Bukittinggi, proyek pembangunan gedung empat (4) lantaiyang tentunya juga memerlukan banyak pekerja dalam pengerjaannya perlu mendapat perhatian serius tentang K3 nya. Oleh sebab itu penelitian tentang Penerapan Kesehatan Dan Keselamatan Kerja (SMK3) Pada Pembangunan Gedung Rawat Inap RSUD Dr. Achmad Mochtar Bukittinggi dilakukan guna mengetahui penerapan Sistem Manajemen Kesehatan dan Keselamatan Kerja (SMK3) pada pelaksanaan Proyek Pembangunan Gedung Rawat Inap RSUD Dr. Achmad Mochtar Bukittinggi dan untuk mengetahui apakah kontraktor pada proyek Pembangunan Gedung Rawat Inap RSUD Dr. Achmad Mochtar Bukittinggi telah menerapkan Sistem Manajemen Kesehatan dan Keselamatan Kerja dalam proses pembangunannya.

\section{METODE PENELITIAN \\ 2.1 Tempat Penelitian}

Penelitian ini dilakukan pada Proyek Pembangunan Gedung Rawat Inap RSUD. Dr. Achmad Mochtar, Jl. Dr. A. Rivai, Bukittinggi, Indonesia.

\subsection{Langkah Penelitian}

\subsubsection{Metode Pengumpulan Data}

Data yang digunakan dalam penelitian ini adalah data primer dan data sekunder. Dari segi proses pelaksanaan pengumpulan data, dengan dokumentasi dan observasi.

\section{a.Data Primer}

Pelaksanaan metode ini dilakukan dengan menggunakan kuisioner yang berisi poin-poin kriteria SMK3 dengan cara pengisian memberikan jawaban pada bagian kanan lembar jawaban berisi kolom checklist, ditambah wawancara bebas dan observasi lapangan yang kemudian dijadikan bahan untuk diolah. 
b. Data Sekunder

Data sekunder merupakan suatu informasi karena merupakan hasil pengolahan data primer dan sudah lebih informatif.

Data sekunder dalam penelitian ini adalah :Kuisioner dimana terdapat dua jenis kuisioner dalam penelitian ini yaitu, kuisioner untuk pihak perusahaan yang berisi daftar pertanyaan berkaitan dengan penerapan SMK3 dan kuisioner untuk pekerja berkaitan dengan pengetahuan mereka tentang K3 dengan jumlah responden 5 orang.

\subsubsection{Instrumen dan Sumber Data Penelitian}

Instrumen penelitian ini menggunakan kuisioner untuk mengevaluasi sejauh mana penerapan Sistem Manajemen Keselamatan dan Kesehatan (SMK3) pada Proyek Pembangunan Gedung Rawat Inap RSUD. Dr. Achmad Mochtar.Penyusunan kuisioner diawali dengan penjabaran menjadi elemen faktor, indikator dan komponenkomponennya. Komponen variabel dijadikan butir-butir pertanyaan. Seluruh butir pertanyaan yang telah selesai disusun dan dimuat dalam lembar instrumen kuisioner. Butir-butir dalam kuisioner berisi item-item implementasi penerapan sistem keselamatan dan kesehatan kerja (SMK3) pada proyek konstruksi bangunan gedung. Dengan cara memberikan jawaban pada bagian kanan lembar jawaban berisi kolom checklist (Sanora,2012).

\subsubsection{Variabel Penelitian}

Variabel yang akan digunakan untuk menghimpun data penerapan sistem keselamatan dan kesehatan kerja (SMK3) pada pembangunan gedung rawat inap RSUD Dr. Achmad Mochtar Bukittinggi mengacu kepada penelitian Sanora (2012).

\subsection{Analisis Data}

Analisis data yang dilakukan pada penelitian ini menggunakan analisa statistik deskriptif yang bertujuan untuk mengubah sekumpulan data mentah menjadi mudah dipahami dalam bentuk informasi yang lebih ringkas. Analisa deskriptif dilakukan setelah responden melakukan pengisian kuisioner tentang penerapan SMK3 pada proyek. Untuk mendapatkan persentase dari penerapan SMK3 dibantu program SPSS Versi 13.Merujuk pada pendapat Ali (1985:184) dalam Sanora (2012) rumus untuk menghitung persentase yang digunakan dalam penelitian ini adalah :

$$
\%=\frac{\mathrm{F}}{\mathrm{N}} \mathrm{X} 100 \%
$$

Keterangan :

$\% \quad$ : Persentase (Jumlah persentase yang dicari)

$$
\begin{array}{ll}
\mathrm{F} & \text { : frekuensi jawaban } \\
\text { responden } & \\
\mathrm{N} & \text { : Jumlah responden } \\
100 \% & \text { : Bilangan tetap }
\end{array}
$$

\section{HASIL PENELITIAN DAN PEMBAHASAN \\ 3.1 Data Responden Penelitian}

Berdasarkan hasil penelitian yang didapatkan dilapangan bahwa responden penelitian terdiri dari 5 orang perwakilan dari unsur pimpinan dan 5 orang perwakilan dari unsur pekerja pada Proyek Pembangunan Gedung Rawat Inap RSUD Dr. Achmad Mochtar Bukittinggi. Beberapa Karakteristik dari responden yaitu : umur, tingkat pendidikan, dan jabatan ditunjukkan secara berurutan pada Gambar 3.1 (a, b, dan c).

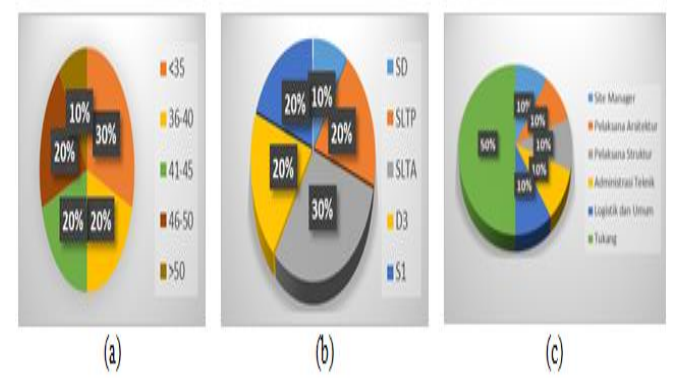

Gambar 3.1. Karakteristik dari responden (a) usia (b) tingkat pendidikan dan (c) jabatan

\subsection{Responden Rate}

Kuisioner disebarkan pada perusahaan dan para pekerja yang mewakili pada pembangunan gedung rawat inap RSUD Dr. Achmad Mochtar Bukittinggi dengan masing-masing diberikan 6 buah kuisioner untuk perwakilan. Dari 12 kuisioner yang 
disebar yang dapat diolah sebanyak 10 kuisioner. Dari hasil tersebut dapat diketahui respon dari penelitian ini dengan menggunakan rumus dalam Sanora (2012), yaitu :

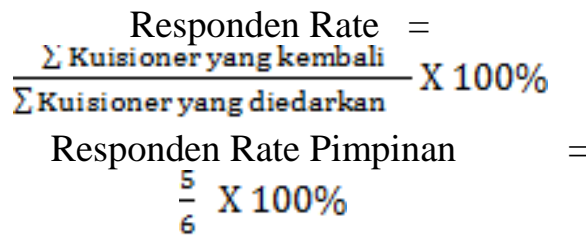

$$
83,33 \%
$$

Responden Rate Pekerja $=$

$$
\frac{5}{6} \times 100 \%=83,33 \%
$$

Hal ini menunjukkan respon yang cukup dari responden terhadap penelitian yang dilakukan.

3.3 Persentase penerapan program K3 (perencanaan, pelaksanaan dan pengawasan pada proyek pembangunan gedung rawat inap RSUD. Dr. Achmad

\begin{tabular}{|c|c|c|c|c|c|}
\hline \multirow{2}{*}{ No. } & \multirow{2}{*}{ Item Pertanyaan } & \multicolumn{2}{|c|}{ Jumlah } & \multicolumn{2}{|c|}{ Persentase } \\
\hline & & YA & TIDAK & YA & TIDAK \\
\hline $\mathrm{X} 1$ & $\begin{array}{l}\text { Apakah perencanasan yang } \\
\text { dibuat mempertimbangkan } \\
\text { identifikasi bahaya pada } \\
\text { proyek yang akan } \\
\text { dilakukan }\end{array}$ & 3 & 2 & $60 \%$ & $40 \%$ \\
\hline $\mathrm{X} 2$ & $\begin{array}{l}\text { Apakah panetapan tujuan } \\
\text { dan sasaran } \\
\text { dikonsultasikan } \\
\text { tengaga ahli }\end{array}$ & 1 & 4 & $20 \%$ & $80 \%$ \\
\hline $\mathrm{X} 3$ & $\begin{array}{l}\text { Apakah perencanaan K3 } \\
\text { terkoordinasi }\end{array}$ & 0 & 5 & $0 \%$ & $100 \%$ \\
\hline $\mathrm{X} 4$ & $\begin{array}{lr}\text { Apaksah } & \text { pengurus } \\
\text { menjelaskan } & \text { peraturan } \\
\text { perundangan } & \text { dan } \\
\text { persyaratan lainnya kepada } \\
\text { setiap pekerja }\end{array}$ & 3 & 2 & $60 \%$ & $40 \%$ \\
\hline $\mathrm{X} 5$ & $\begin{array}{l}\text { Apakah para pekerja } \\
\text { menyadari akan pentingnya } \\
\text { K3 }\end{array}$ & 1 & 4 & $20 \%$ & $80 \%$ \\
\hline $\mathrm{X} 6$ & $\begin{array}{l}\text { Apakah catatan inspeksi, } \\
\text { pengujian dan pemantauan } \\
\text { terpelihara dengan baik }\end{array}$ & 2 & 3 & $40 \%$ & $60 \%$ \\
\hline $\mathrm{X} 7$ & $\begin{array}{l}\text { Apakah tujuan dan sasaran } \\
\text { K3 yang ditetapkan } \\
\text { ditinjau secara teratur }\end{array}$ & 2 & 3 & $40 \%$ & $60 \%$ \\
\hline $\mathrm{X} 8$ & $\begin{array}{l}\text { Apakah petugas } \mathrm{K} 3 \text { selalu } \\
\text { meninjau lokasi kerja }\end{array}$ & 0 & 5 & $0 \%$ & $100 \%$ \\
\hline $\mathrm{Xg}$ & $\begin{array}{l}\text { Apakah pelaksanaan audit } \\
\text { SMK3 dilakukan secara } \\
\text { berkala }\end{array}$ & 1 & 4 & $20 \%$ & $80 \%$ \\
\hline $\mathrm{X} 10$ & $\begin{array}{lr}\text { Apaksh perusahasn } \\
\text { menggunakan indikator } \\
\text { kinerja yang daost diukur } \\
\text { sebagai dasar penilaian } \\
\text { kinerja K3 }\end{array}$ & 2 & 3 & $40 \%$ & $60 \%$ \\
\hline & RATA-RATA & & & $24 \%$ & $76 \%$ \\
\hline
\end{tabular}
Mochtar Bukittinggi

Dari hasil pengolahan data bagaimana penerapan program K3 (perencanaan, pelaksanaan dan pengawasan pada proyek pembangunan gedung rawat inap RSUD. Dr. Achmad Mochtar Bukittinggi, diperoleh $24 \%$ responden menjawab YA dan $76 \%$ responden menjawab TIDAK. Dari kriteria penerapan termasuk kategori kurang diterapkan. Hal ini disebabkan karena tidak adanya perencanaan K3 yang terkoordinasi, tidak adanya petugas khusus K3 di lapangan dan juga karena pihak manajemen kurang menyadari pentingnya K3.

\subsection{Persentase Penerapan proses manajemen Kesehatan dan Keselamatan Kerja}

Dari hasil pengolahan data bagaimana Penerapan proses manajemen Kesehatan dan Keselamatan Kerja pada Proyek pembangunan Gedung Rawat Inap RSUD Dr. Achmad Mochtar Bukittinggi, diperoleh $20 \%$ responden menjawab YA dan $80 \%$ responden menjawab TIDAK. Dan termasuk pada kategori sangat kurang diterapkan, hal ini dikarenakan adanya kendala-kendala seperti pelaksana proyek tidak memiliki operasi standar $\mathrm{K} 3$, tidak adanya organisasi k3 di lapangan dan tidak adanya ketentuan untuk mengkomunikasikan $\mathrm{k} 3$ secara efektif

\subsection{Persentase Ketersediaan Sumber Daya} K3

Dari hasil pengolahan data bagaimana Ketersediaan Sumber Daya K3 (Kesehatan dan Keselamatan Kerja) Pada Proyek Pembangunan RSUD Dr. Achmad Mochtar Bukittinggi diperoleh 46,67\% reponden menjawab YA dan 53,33\% responden menjawab TIDAK dan termasuk dalam kategori cukup diterapkan. Masih kurangnya penerapan keterediaan sumber daya K3 ini diantaranya disebabkan oleh kurangnya kesadaran pekerja akan pentingnya $\mathrm{K} 3$, kurangnya papan tanda $\mathrm{K} 3$ dan rambu-rambu peringatan K3 di lapangan serta tidak ada personel yang jelas dalam penanganan $\mathrm{K} 3$.

\subsection{Persentase penerapan Pelatihan dan Sumber Daya K3}

Dari hasil pengolahan data tentang bagaimana penerapan Pelatihan K3 pada Proyek Pembangunan Gedung Rawat Inap RSAM diperoleh $0 \%$ responden yang menjawab YA, hal ini dikarenakan tidak ada pelatihan K3 diawal proyek dan tidak ada pelatihan K3 untuk kegiatan yang memiliki resiko cukup besar.Dari hasil pengolahan data tentang bagaimana penerapan Sumber 
Daya K3 pada pembangunan gedung rawat inap RSUD Dr. Achmad Mochtar Bukittinggi diperoleh $40 \%$ responden menjawab YA dan $60 \%$ responden menjawab TIDAK. Dan termasuk pada kategori kurang diterapkan. Hal ini disebabkan oleh beberapa kendala diantaranya tidak ada papan tanda dan rambu-rambu K3 di lapangan, kurangnya kelengkapan APD seperti sabuk pengaman dan alat penangkal petir serta tidak ada penekanan dan sanksi tegas dalam pemakaian APD.

\section{SIMPULAN}

Berdasarkan hasil penelitian tentang sejauh mana penerapan Sistem Kesehatan dan Keselamatan Kerja pada Pembangunan Gedung Rawat Inap RSUD Dr. Achmad Mochtar Bukittinggi dapat diperoleh kesimpulan bahwa : (1) Penerapan Sistem Manajemen Kesehatan dan Keselamatan Kerja (SMK3) pada proyek ini kurang diterapkan, hal ini terlihat dari jawaban dan tanggapan dari unsur perusahaan dan unsur pekerja yang setelah dirata-ratakan didapat persentase $26.13 \%$. Hal ini disebabkan oleh tidak adanya perencanaan K3 yang terkoordinasi, tidak adanya petugas khusus K3 di lapangan, pihak manajemen juga kurang menyadari pentingnya $\mathrm{K} 3$, tidak ada personel yang jelas dalam penanganan $\mathrm{K} 3$, dan tidak ada penekanan dan sanksi tegas dalam pemakaian APD sehingga masih banyak pekerja yang mengabaikan penggunaan APD. (2)Kontraktor pada Pembangunan Gedung Rawat Inap RSUD Dr. Achmad Mochtar Bukittinggi tidak menerapkan Sistem Manajemen Kesehatan dan Keselamatan Kerja (SMK3) dalam proses pembangunan, hal ini dikarenakan kurangnya pemahaman pihak-pihak terkait mengenai pentingnya Kesehatan dan Keselamatan Kerja dan terbatasnya anggaran perusahaan juga terlihat menjadi kendala dalam pelaksanaan K3 di Proyek.

\section{DAFTAR PUSTAKA}

Messah.Y.A., Yohana Bolu Tena., I Made Udiana, 2012, Kajian Implementasi Sistem Manajemen Keselamatan Dan Kesehatan Kerja Pada Perusahaan Jasa Konstruksi Di Kota Kupang,
Jurnal Teknik Sipil Vol. 1 No. 4, hal 101-114,

Pangkey. F., Grace Y. Malingkas, D.O.R. Walangitan, 2012, Penerapan Sistem Manajemen Keselamatan Dan Kesehatan Kerja (Smk3) Pada Proyek Konstruksi Di Indonesia (Studi Kasus: Pembangunan Jembatan Dr. Ir. Soekarno-Manado), Jurnal Ilmiah MEDIA ENGINEERING Vol. 2, No. 2 hal. 100-113, ISSN: 2087-9334.

Ramadhan. A., 2012, Penerapan Sistem Manajemen Keselamatan dan Kesehatan Kerja (SMK3) ( Studi Pada Proyek Pembangunan Jalan Rawa Buaya, Cengkareng), Skripsi, Universitas Indonesia, Depok

Sanora, Well Of. 2012. Implementasi Kesehatan dan Keselamatan Kerja pada proyek Konstruksi Bangunan Milik Pemerintah di Kota Padang. Tesis Program Pascasarjana : Universitas Bung Hatta

Sihombin. D., D. R. O. Walangitan, Pingkan A. K. Pratasis, 2014, Implementasi Keselamatan Dan Kesehatan Kerja (K3) Pada Proyek Di Kota Bitung (Studi Kasus Proyek Pembangunan Pabrik Minyak Pt.Mns), Jurnal Sipil Statik Vol.2 No.3 hal. 124-130 ISSN: 2337-6732.

Susihono. W., F. Rini. A., 2013, Penerapan Sistem Manajemen Keselamatan Dan Kesehatan Kerja (K3) Dan Identifikasi Potensi Bahaya Kerja (Studi Kasus Di Pt. Ltx Kota Cilegon- Banten), Jurnal Spektrum Industri, 2013, Vol. 11, No. 2, hal. $117-242$, ISSN : 1963-6590

Taufik. H., Trikomara. R., Efpridawati., 2015, Tinjauan Penerapan Sistem Manajemen Keselamatan Dan Kesehatan Kerja (Smk3) (Studi Kasus: Pembangunan Gedung Telkomsel Pekanbaru), Annual Civil Engineering Seminar, Pekanbaru, ISBN: 978-979-792-636-6. 